\title{
Protocolo de Tratamento Fisioterápico da Dinâmica Respiratória em Pacientes com Lesão Medular Completa em Diferentes Níveis Cervicais e Torácico Baixo
}

\author{
Valdinéia Cândida Pereira*, Sissy Veloso Fontes **, \\ José Augusto Perez ${ }^{* * *}$, Marcia Maiumi Fukujima ${ }^{* \star * *}$
}

\section{RESUMO}

A lesão medular é um evento devastador que ocorre em todos os países do mundo, independentemente do nível socioeconômico. No Brasil, a maioria das lesões são causadas por acidentes automobilísticos, e mais freqüentemente são completas no nível de $\mathrm{C} 5-\mathrm{C} 7$, causando tetraplegia. As lesões cervicais e torácicas altas causam a paralisia dos músculos abaixo do nível da lesão, dentre eles importantes músculos respiratórios, desta forma, as alterações respiratórias nestes pacientes são muito comuns e, em decorrência destas, surgem comprometimentos da função pulmonar, constituindo as causas mais comuns de incapacidade e morte. O tratamento fisioterápico respiratório é imprescindível e deve ser iniciado o mais precocemente possível e continuado por toda a vida do indivíduo, visando tanto ao tratamento profilático quanto ao curativo; porém, para que o tratamento obtenha maior efetividade, deve conter um programa específico para cada nível de lesão, já que as alterações biomecânicas dependem diretamente desse fator.

\section{UNITERMOS}

Lesão medular, fisioterapia respiratória.

* Educadora Física e Fisioterapeuta

** Educadora Física e Fisioterapeuta, Docente da Universidade Bandeirante de São Paulo e da Universidade Santa Cecília.

*** Fisioterapeuta, Diretor do Departamentoto de Ciências da Saúde do Centro Universitário Nove de Julho.

**** Neurologista, Docente da Universidade Bandeirante de São Paulo e da Universidade Santa Cecília.

\section{INTRODUÇÃO}

No Brasil e em outros países, a maioria das lesões medulares são causadas por acidentes automobilísticos, e mais freqüentemente são completas no nível de C5-C7, causando tetraplegia ${ }^{1,10}$.

O envolvimento respiratório representa um aspecto particularmente grave e pode ser fatal aos pacientes com lesão da medula espinhal. Cabe lembrar que as complicações pulmonares, como broncopneumonia ${ }^{1,7,10}$. Através de um estudo prospectivo em 1996, no estado de Colorado, no Estados Unidos da América $^{5}$, foi descrito que os maiores custos dispensados a pacientes com lesão medular são decorrentes de complicações respiratórias, neurológicas, dermatológicas e ortopédicas. A lesão medular foi causa de ventilação mecânica prolongada em $20 \%$ dos pacientes estudados ${ }^{2}$. Há poucas referências que abordam o tratamento respiratório de pacientes com lesão medular. Observamos que tais pacientes, independentemente do nível de lesão seguem um mesmo programa de tratamento fisioterápico respiratório. A lesão medular é apontada como uma incapacitação de baixa incidência e alto custo, que promove alterações na qualidade de vida do paciente devido ao seu comprometimento multissistêmico, sendo, portanto, considerada uma das lesões mais incapacitantes do ponto de vista social, econômico e físico ${ }^{1,10}$. No que diz respeito à fisiopatologia da dinâmica respiratória, pode-se dizer que a maioria dos pacientes paraplégicos de nível alto e todos os pacientes tetraplégicos apresentam uma diminuição da função respiratória imediatamente após a lesão, que eventualmente leva a um nível de função cardiorrespiratória a longo prazo significantemente diferente do seu estado pré-mórbido. Esse estado alterado corresponde em gravidade ao nível da lesão e às funções remanescentes dos músculos respiratórios. Infecção respiratória e embolia pulmonar são responsáveis por uma elevada incidência 
de mortalidade durante os estágios iniciais da lesão ${ }^{1,10}$.Tais complicações, quando abordadas precocemente pelo fisioterapeuta através de cuidados não invasivos da musculatura respiratória remanescente, poderão prevenir a falência respiratória ${ }^{11}$.

\section{OBJ ETIVO}

Abordar os princípios de tratamento fisioterápico respiratório para o nível de lesão correspondente de cada segmento medular, comparando-os e propondo um protocolo cinesioterápico de modo a beneficiar os músculos remanescentes.

\section{MÉTODO}

Elaboração de protocolo de tratamento fisioterápico respiratório com base nos diferentes quadros clínicos e funcionais de pacientes com lesão medular no nível do $4^{\circ}$. segmento medular cervical (C4) ou do $7^{\circ}$. segmento medular cervical (C7), ou do $12^{\circ}$. segmento medular torácico (T12), por etiologia traumática sem pneumopatias adjacentes.

\section{RESULTADOS}

O protocolo de tratamento proposto para os diferentes níveis de lesão medular (C4, C7 e T12) foi dividido em: profilaxia, que visa aumentar a reserva respiratória de forma a propiciar melhores condições pulmonares evitando problemas respiratórios que possam surgir; terapia de ataque, que visa melhorar a força muscular respiratória das estruturas remanescentes, propiciando uma dinâmica respiratória mais efetiva; e terapia de manutenção, que visa melhorar a resistência dos músculos respiratórios, beneficiando significativamente a capacidade pulmonar total (CPT), como mostram os quadros 1,2 e 3 .

Este protocolo permite planejarmos a intervenção fisioterápica mais adequada, ou seja, de acordo com o nível da lesão medular e seu momento clínico, de forma a propiciar um tratamento mais especializado.

\section{DISCUSSÃO}

Ao abordarmos os diferentes níveis de lesão medular, pudemos observar com base na literatura as diversas complicações respiratórias correspondentes a cada nível

\begin{tabular}{|c|c|c|}
\hline \multicolumn{3}{|c|}{ QUADRO 1} \\
\hline Alterações biomecânicas & Fases e objetivos do tratamento & Fisioterapia respiratória \\
\hline & Profilática & \\
\hline $\begin{array}{l}\text { - diminuição significante da } \\
\text { capacidade vital } \\
\text { - manutenção do volume pelo aumento } \\
\text { da frequiência respiratória } \\
\text { - aumento do gasto energético }\end{array}$ & $\begin{array}{l}\text { - evitar atelectasia nos pulmões } \\
\text { - evitar retenção de secreções na } \\
\text { árvore brônquica }\end{array}$ & $\begin{array}{l}\text { - posicionamentos associados ao } \\
\text { ventilador mecânico tipo BIRD (RPPI) } \\
\text { - cinesioterapia } \\
\text { - inaloterapia } \\
\text { - manobras de higiene brônquica } \\
\text { - drenagem postural }\end{array}$ \\
\hline
\end{tabular}

Terapia de Ataque

- ausência do ato de suspirar

- alteração na fixação do centro frênico

- tosse incompetente
- treino de endurance do músculo diafragma • fortalecimento do músculo diafragma

- treino de huffing (retração elástica)

Manutenção

- preservar as condições respiratórias satisfatórias do paciente
- treino de endurance $(50 \%$ a $60 \%$ da carga máxima), aumentando o tempo de execução do trabalho muscular ( $\mathrm{n}^{\circ}$ de repetições)

RPPI - Respiração por Pressão Positiva Intermitente. 
medular ${ }^{3,6,8,9}$; sendo assim, em uma lesão completa de C4 o paciente apresentará paralisia da musculatura torácica (músculos intercostais, músculos abdominais não atuantes e fraqueza da musculatura diafragmática). O diafragma passa a funcionar menos do que o normal, devido à preservação parcial de suas raízes. Quando o padrão respiratório é observado, há uma elevação epigástrica (contração do músculo diafragmático), sem expansão torácica, diminuindo a mobilidade e a elasticidade. Entretanto, a contração da musculatura acessória inspiratória é bastante evidente. Essa contração ativa dos músculos acessórios indica que somente a função diafragmática é muito fraca para manter o volume corrente adequado. Quando o paciente apresentar tal respiração acessória, o volume corrente e a capacidade vital (CV) muitas vezes estarão iguais; podemos dizer que este fato ocorre devido ao diafragma apresentar um grau de força muscular diminuído. O paciente apresentará uma resistência muscular respiratória menor, ou seja, fadigará mais rapidamente do que um paciente que utiliza o músculo diafragma de forma eficiente, pois a ventilação com a atuação do diafragma possui um gasto energético menor do que a ventilação que utiliza em demasia a musculatura acessória. Em lesão de C4 ocorre um aumento da freqüência respiratória para manter a ventilação alveolar adequada e evitar hipoventilação, que pode ocorrer por força inadequada da musculatura respiratória. Esse fator de aumento da freqüência respiratória torna-se também o colaborador para o aumento do gasto energético e, portanto, potencialmente capaz de levar o paciente a fadiga.

Pacientes com lesão em C7 respiram sem assistência dos músculos intercostais e dependem totalmente do músculo diafragma. A paralisia dos músculos intercostais resultará na redução da expansão torácica e no volume inspiratório reduzido. A capacidade ventilatória do paciente torna-se descoordenada, e os músculos acessórios da respiração (músculos esternocleidomastóideo, trapézio, escalenos, peitoral menor e serrátil anterior) progressivamente entram em ação. A expiração também não ocorre fisiologicamente; os músculos abdominais, primários da expiração, estão comprometidos; a eficiência expiratória forçada diminui significantemente, porque os músculos abdominais quando completamente inervados exercem um importante papel na manutenção da pressão intratorácica e

QUADRO 2

Proposta de tratamento fisioterápico respiratório no lesado medular - nível C7

\begin{tabular}{lll}
\hline Alterações biomecânicas & Fases e objetivos do tratamento & Fisioterapia respiratória \\
\hline & Profilática & \\
\hline - moderada diminuição da & $\bullet$ evitar atelectasia nos pulmões & $\bullet$ posicionamentos associados ao \\
capacidade vital & $\bullet$ evitar retenção de secreções na & ventilador mecânico tipo BIRD (RPPI) \\
& $\begin{array}{l}\text { árvore brônquica } \\
\bullet \text { inaloterapia }\end{array}$ & $\bullet$ manobras de higiene brônquica \\
& & $\bullet$ drenagem postural \\
& & cinesioterapia (trabalho muscular \\
& incrementado com carga linear e alinear)
\end{tabular}

Terapia de Ataque

- ausência do suspiro

- déficit no mecanismo da tosse

- diminuição do endurance (resistência)
- melhora da força dos músculos respiratórios remanescentes
- treino de endurance $(50 \%$ a $70 \%$ da carga máxima), aumento do tempo do exercício com uma carga moderada - exercícios respiratórios com inspiração sustentada (incentivador linear) (exercícios visando edurance + trofismo)

Manutenção

- aumento da resistência dos músculos respiratórios remanescentes
- manter exercícios com 50\% a 70\% da carga máxima, visando endurance

RPPI - Respiração por Pressão Positiva Intermitente. 
abdominal. Os músculos abdominais estabilizam as vísceras abdominais e auxiliam na manutenção da posição do diafragma para cima durante a expiração forçada. Com a paralisia dos músculos abdominais, altera-se a dinâmica da ventilação, modificando a biomecânica do diafragma. Este assume uma posição rebaixada devido à falta de pressão que os músculos abdominais exercem sobre o diafragma durante a expiração, o que resulta em uma redução do volume de reserva expiratória. A perda da função dos músculos intercostais internos, cuja função na expiração consiste na depressão da caixa torácica, faz com que a habilidade do paciente em expirar e de promover tosse e expectoração tornem-se prejudicadas. Nessas condições, o diafragma torna-se o único músculo ativo e o paciente é considerado "respirador diafragmático". Se não houver tratamento adequado o paciente pode apresentar alterações posturais a longo prazo, significativa diminuição da mobilidade torácica, respiração descoordenada, o que pode resultar em problemas sistêmicos agudos ou crônicos.

Os grupos musculares do pescoço, do tórax, do abdome e o diafragma contribuem para uma respiração normal. O padrão respiratório normal consiste em expansão torácica e elevação epigástrica. A expansão torácica é resultante da contração dos músculos intercostais externos e a elevação epigástrica resulta da contração do músculo diafragmático. Pacientes com lesões torácicas baixas, como lesão em T12, aproximamse do padrão respiratório normal, pois os músculos intercostais trabalham eficientemente para elevação torácica, e, com os músculos abdominais completamente inervados, mantêm-se a pressão intratorácica e intraabdominal normais, tendo então uma respiração efetiva. Porém, inicialmente (fase de choque medular) esses pacientes apresentam diminuição da expansibilidade torácica. Todos os músculos da expiração estarão inervados, mas clinicamente a mensuração da expansão da caixa torácica no nível do processo xifóide será em torno de 5 a $6,5 \mathrm{~cm}$, sendo que os valores normais da expansão giram em torno de $8 \mathrm{~cm}$. Essa diminuição da atividade da musculatura inspiratória logo após a lesão é transitória e os valores normais para expansão torácica retornam mais rapidamente quando submetidos a programas de reabilitação respiratória intensiva. Portanto, não existem a médio ou a longo

\section{QUADRO 3}

Proposta de tratamento fisioterápico respiratório no lesado medular - nível T12

\begin{tabular}{lll}
\hline Alterações biomecânicas & Fases e objetivos do tratamento & Fisioterapia respiratória \\
\hline & Profilática & \\
\hline - alterações funcionais transitórias & • prevenir complicações advindas & $\bullet$ inaloterapia com água destilada \\
(fase de choque medular) - & da fase de choque e melhora da & $\bullet$ posicionamentos + BIRD (RPPI) \\
diminuição da capacidade & condição postural, devido à pouca & $\bullet$ manobras de higiene brônquica \\
pulmonar total e expansão do & estabilidade pelvicoabdominal & $\bullet$ drenagem postural \\
mecanismo pulmonar & & $\bullet$ mobilização passiva de membros \\
& & inferiores associados com exercícios \\
& & respiratórios
\end{tabular}

Terapia de Ataque

- desarranjos posturais

- exercícios para os músculos de manutenção da postura de músculos respiratórios
- exercícios ativos livres e resistidos de membros superiores associados com exercícios respiratórios

- treino de atividades de vida diária, visando ao aumento da resistência dos músculos respiratórios ao esforço

Manutenção

- exercícios de resistência e de fortalecimento dos músculos respiratórios
- atividade física (de preferência esportiva)

2 vezes por semana

RPPI - Respiração por Pressão Positiva Intermitente. 
prazo alterações significativas da CPT, tendo-se em vista que a estrutura funcional manteve-se preservada, deixando as alterações estáticas (volumes e capacidades) como conseqüência da fase de choque medular e/ou eventualmente por desarranjos posturais adquiridos após a lesão.

Observamos que existem diferenças na abordagem terapêutica nos diferentes níveis de lesão medular. Em T12, por exemplo, a fisioterapia é totalmente diferenciada quando relacionados aos segmentos $\mathrm{C} 4$ e C7. Em T12 existe uma progressão tanto para o trabalho de fortalecimento quanto no desenvolvimento da resistência, preocupando-se justamente com o efeito sobre a função cardiorrespiratória. Já no que se refere aos níveis C4 e C7, nota-se que a profilaxia e a manutenção se processam da mesma maneira, tendo uma acentuada diferenciação no que diz respeito à terapia de ataque. Em nível C4 a terapia de ataque visa ao ganho de força muscular e por conseqüência ganho de resistência, enquanto em $\mathrm{C} 7$ visa-se mais ao treino de endurance (resistência), aumentando o poder de contração da musculatura remanescente ${ }^{4}$.

Portanto, é necessário o conhecimento anatômico e funcional para eleger os melhores métodos de tratamento fisioterápico nos diferentes níveis de lesão.

\section{SUMMARY}

Respiratory Physical Therapy for Patients with Complete Cervical and Thoracic Spinal Cord Injury

Spinal cord injury is a devastating event which happens all over the world. Most of the injuries have been caused by car accidents. The most frequent lesions are complete spinal cord injures at the level of $\mathrm{C} 5-\mathrm{C} 7$, causing tetraplegy. The cervical and high thoracic spine injuries cause paralyses of the muscles below the level of the lesion, affecting frequently some of these muscles. The lung dysfunction are the most frequent causes of incapacity and death. That is why the physiotherapic respiratory treatment must start as soon as possible and continue for the patients hole life, aiming at the prophylactic and healing treatment.

\section{KEY WORD}

Spinal cord injury, respiratory physiotherapy.

\section{Referências}

1. Annunthred, D.; Schneider, F.J. Lesão medular traumática. In: Annunthred, D. Fisioterapia neurológica. São Paulo, Manole, 1994, p. 421-479.

2. Fraser, J.; Henrichsen, T.; Mok, Q.; Tasker, R.C. Prolonged mechanical ventilation as a consequence of acute illness. Arch Dis Child, 78(3): 253-6, 1998.

3. Howard, R.S.; Thorpe, J.; Barker, R.; Revesz, T. et al Respiratory insufficiency to high anterior cervical cord infarction. J Neurol Neurosurg Psyquiatry, 64(3): 358-61, 1998.

4. Irwin, S.; Tecklin, J.; Wetzel, J.L.; Lunsford, R.B. et al. Reabilitação respiratória no paciente com lesão da medula espinhal. In: Irwin, S.; Tecklin, J. Fisioterapia cardiopulmonar. São Paulo, Manole, 1994, p. 513-537.

5. Johnson, R.L.; Brooks, C.A.; Whiteneck, G.G. Cost of traumatic spinal cord injury in a population-based registry. Spinal Cord, 34(8): 470-80, 1996.

6. Lissens, M.A.; Vanderstraeten, G.G. Motor evoked potentials of the respiratory muscles in tetraplegic patients. Spinal Cord, 34(11): 373-8, 1996

7. Pajareya, K. Traumatic spinal cord injuries in Thailand: an epidemiologic study in Siriraj Hospital, 1989-1994. Spinal Cord, 34(10): 608-10, 1996.

8. Rutchik, A.; Weissman, A.R.; Almenoff, P.L.; Spungen, A.M. et al. Resistive inspiratory muscle training in subjects with chronic cervical spinal cord injury. Arch Phys Med Rehabil, 79(3): 293-7, 1998.

9. Sannohe, A.; Harata, S.; Ueyama, K.; Ito, J. et al. The prognosis and the treatment of patients with a C3/4 spinal cord injury. Spinal Cord, 34(8): 486-7, 1996.

10. Sullivan, O.B.; Schimitz, S.; Murray, M.F.; Thomas, J. Lesões traumáticas congênitas da medula espinhal. In: Sullivan, O.B. Fisioterapia, avaliação e tratamento. São Paulo, Manole, 1993, p. 709-725.

11. Viroslav, J.; Rosenblatt, R.; Tomazevic, S.M. Respiratory management, survival, and quality of life for high-level traumatic tetraplegics. Respir Care Clin N Am, 2(2): 313-22, 1996.

Endereço para correspondência:

Marcia Maiumi Fukujima

Rua Arnoldo Baldoíno Welter, 75 - ap. 52

CEP 04310-070 São Paulo (SP)

E-mail: maiumi@sti.com.br ou sissy@sun-nepi.epm.br 